\title{
Evidence for a Mitral Valve Origin of the Left Ventricular Third Heart Sound
}

\author{
JAMES S. FLEMING \\ From the Cardiac Department, St. Bartholomew's Hospital, London E.C.1
}

A low frequency sound at the cardiac apex in early diastole is a characteristic feature of severe mitral incompetence and may also be present in left ventricular disease due to hypertension, ischaemia, or cardiomyopathy. The commonly used description "ventricular filling sound" implies that vibrations from the left ventricle are responsible for the production of the sound, and this has been the view of Potain (1900), Crevasse et al. (1962), and Kuo et al. (1957). Many workers, however, regard the third heart sound as originating from the mitral valve, and suggest that the mechanism is early closure of the valve (Gibson, 1907; Thayer, 1909) or a sudden tautening of the valve in early diastole (Dock, 1959; Nixon, 1961).

In the present study, the role of the mitral valve in the production of the third heart sound has been further investigated by obtaining simultaneous records of the phonocardiogram and of the movements of the cardiac apex in patients with mitral incompetence before and after the mitral valve had been excised and replaced by a Starr-Edwards prosthesis. From the observed effects, the important part played by the mitral valve in the production of the third heart sound can be assessed.

If the third heart sound is caused by early closure of the mitral valve, the valve must be fully closed at the time of the sound. The hypothesis that the third heart sound is a valve closure sound was tested in these patients with mitral incompetence by defining the position of the anterior leaflet of the mitral valve at the time of the sound.

\section{Patients and Methods}

Studies were made of 23 patients aged 20 to 60 , with severe mitral incompetence as the sole or dominant

Received August 5, 1968. lesion. Three patients gave a history of previouslytreated bacterial endocarditis, one patient had idiopathic rupture of the chordae tendineae, and in the remaining 19 , the lesion was typical rheumatic mitral incompetence. Atrial fibrillation was present in all the rheumatic patients and the other 4 remained in sinus rhythm. A loud pansystolic murmur maximal at the cardiac apex, a third heart sound, and considerable cardiac enlargement on the chest $x$-ray were features common to all. The diagnosis was confirmed in each case by cardiac catheterization and left ventricular angiocardiography, and by inspection of the mitral valve at open-heart surgery.

Before operation, simultaneous recordings of the apex cardiogram, the phonocardiogram, and the electrocardiogram were made using a photographic recorder at a paper speed of $80 \mathrm{~mm}$. a second. The apex cardiogram was obtained using a Philips displacement transducer as described previously (Fleming and Hamer, 1967), and the phonocardiogram was recorded from a crystal microphone applied to the chest wall by suction just medial to the cardiac apex.

In all patients the low frequency vibrations of a third heart sound were identified, beginning 0.10 to $0.17 \mathrm{sec}$. after aortic valve closure and coinciding with a peak in the diastolic phase of the apex cardiogram (Fig. 1). This peak on the apex cardiogram, indicating the point where the rapid outward motion of the ventricle in early diastole is abruptly checked, is followed by a slight inward movement of the cardiac apex, and was present in all patients. The abrupt retraction of the cardiac apex occurs simultaneously with the third heart sound, and the peak on the apex cardiogram representing this retraction is referred to as the third sound point. The height of this point has been expressed as a percentage of the total amplitude of the apex cardiogram, thus allowing comparison between patients and avoiding the need for calibration of the apex cardiogram in terms of absolute displacement. The apex cardiogram, phonocardiogram, and electrocardiogram were recorded again 4 weeks or more after mitral valve replacement with a StarrEdwards caged ball valve prosthesis.

Movements of the anterior leaf of the mitral valve were detected by the technique of reflected ultrasound. 


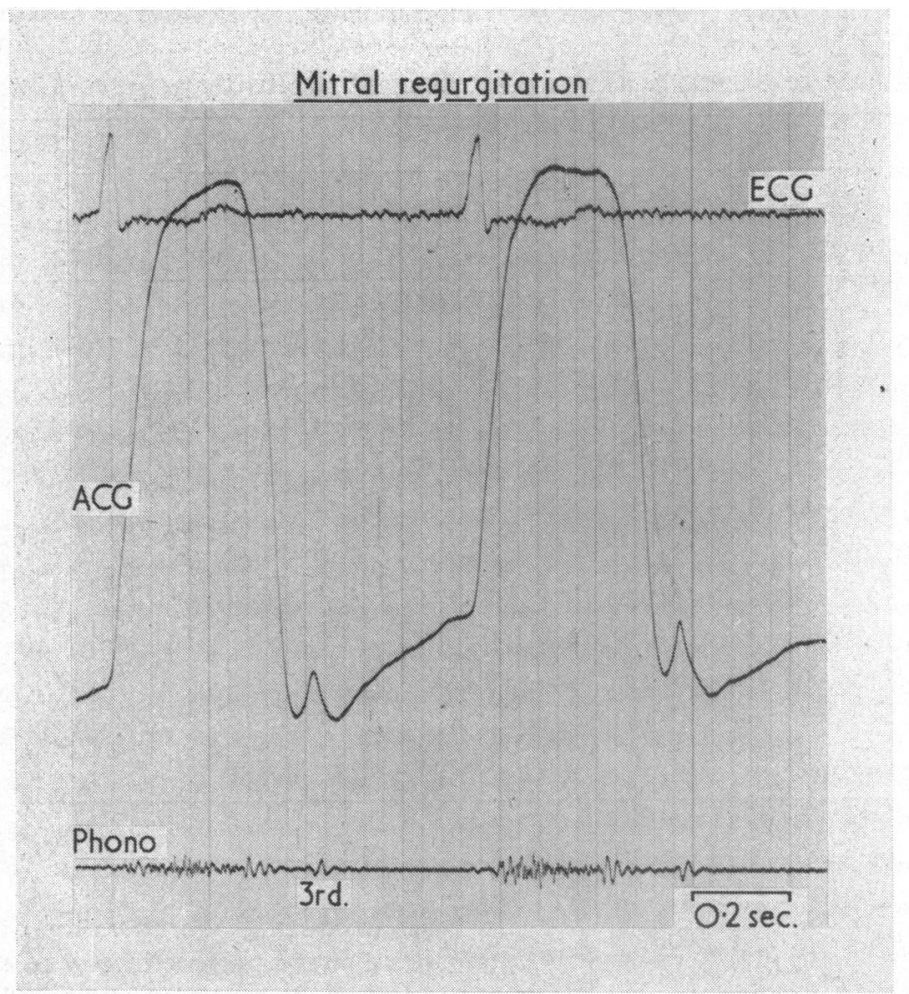

FIG. 1.-Simultaneous phonocardiogram, apex cardiogram, and electrocardiogram. Third heart sound recorded $0.16 \mathrm{sec}$. after aortic valve closure, coinciding with diastolic peak on the apex cardiogram (ACG).

The Eskoline 20 ultrasonoscope was used, with the sound generating crystal held in the third left intercostal space $1-4 \mathrm{~cm}$. lateral to the sternal edge, and the echo from the anterior leaflet was identified by its characteristic rapid movement, of about $2 \mathrm{~cm}$. in total amplitude, some 6 to $8 \mathrm{~cm}$. from the anterior chest wall (Fig. 2). The echo from the mitral valve was displayed on the oscilloscope of the instrument as an intensity modulated trace together with an electrocardiographic signal (lead II), and a photographic film was exposed during one fast sweep cycle $(60 \mathrm{~mm}$. per second). In this way, a composite picture was obtained of the motion pattern of the anterior leaflet of the mitral valve, and the position of the leaflet at any point of the cardiac cycle can be obtained using the electrocardiogram as a reference. The ultrasound cardiogram was obtained within 5 minutes of recording the apex cardiogram and, in patients in sinus rhythm where heart cycle lengths were virtually constant, the echocardiogram was traced onto the apex cardiogram and phonocardiogram record.

In 8 patients aged 25 to 50 with aortic valve disease the apex cardiogram, phonocardiogram, and electrocardiogram were recorded 4 weeks or more after aortic valve replacement with a Starr-Edwards caged ball prosthesis. The movements of the cardiac apex in these patients, in whom the mitral valve was intact, were compared with the records obtained from the patients whose mitral valves had been replaced.

\section{Results}

Mitral Regurgitation (Table I). Before operation low frequency vibrations of a third heart sound, occurring $0 \cdot 10-0.17 \mathrm{sec}$. after aortic valve closure, were recorded on the phonocardiogram in all 23 patients. In early diastole the rapid outward movement of the cardiac apex was abruptly checked and followed by a small inward movement, producing a peak in early diastole on the apex cardiogram. This peak coincided in time with the vibrations of the third heart sound in every case (Fig. 1).

The movements throughout the cardiac cycle of the anterior leaf of the mitral valve were recorded by reflected ultrasound in 5 patients with mitral incompetence, and a typical recording at slow and fast sweeps is shown in Fig. 3. When these movements of the anterior leaflet of the mitral valve were related to the phonocardiogram (Fig. 4), it was seen that at the time of the third heart sound the anterior leaflet of the mitral valve had almost completed the phase of rapid posterior movement and was in an intermediate position, approximately halfway between the fully open and fully closed positions.

After surgical excision of the mitral valve and replacement with a Starr-Edwards prosthesis no 
TABLE I

APEX CARDIOGRAM AND PHONOCARDIOGRAM IN 23 PATIENTS WITH MITRAL INCOMPETENCE

\begin{tabular}{|c|c|c|c|c|c|}
\hline \multirow[b]{2}{*}{ Patient } & \multicolumn{2}{|r|}{ Before operation } & \multicolumn{3}{|c|}{ After valve replacement } \\
\hline & 3rd sound & Total ACG deflection $0 / 0$ & 3rd sound & Height of 3rd sound point & $0 / 0$ \\
\hline $\begin{array}{l}\text { E.A. } \\
\text { J.B. } \\
\text { T.B. } \\
\text { D.B. } \\
\text { E.B. } \\
\text { P.B. } \\
\text { T.B. } \\
\text { J.C. } \\
\text { B.C. } \\
\text { E.G. } \\
\text { G.H. } \\
\text { H.H. } \\
\text { B.K. } \\
\text { B.L. } \\
\text { R.M. } \\
\text { G.M. } \\
\text { B.M. } \\
\text { A.R. } \\
\text { G.R. } \\
\text { A.S. } \\
\text { A.T. } \\
\text { B.W. } \\
\text { H.W. }\end{array}$ & $\begin{array}{l}+ \\
+ \\
+ \\
+ \\
+ \\
+ \\
+ \\
+ \\
+ \\
+ \\
+ \\
+ \\
+ \\
+ \\
+ \\
+ \\
+ \\
+ \\
+ \\
+ \\
+ \\
+ \\
+\end{array}$ & $\begin{array}{r}9 \\
12 \\
18 \\
10 \\
21 \\
22 \\
5 \\
7 \\
28 \\
7 \\
9 \\
3 \\
30 \\
10 \\
9 \\
12 \\
10 \\
14 \\
10 \\
6 \\
14 \\
21 \\
31\end{array}$ & $\begin{array}{l}\bar{z} \\
\bar{z} \\
\bar{z} \\
\bar{z} \\
\bar{z} \\
\bar{z} \\
\bar{z} \\
\bar{z} \\
\bar{z} \\
\bar{z} \\
\bar{z} \\
\bar{z} \\
\bar{z}\end{array}$ & $\begin{array}{l}\bar{z} \\
\bar{z} \\
\bar{z} \\
\bar{z} \\
\bar{z} \\
\bar{z} \\
\bar{z} \\
\bar{z} \\
\bar{z} \\
\bar{z} \\
\bar{z}\end{array}$ & \\
\hline
\end{tabular}

low frequency vibrations of the usual third heart

Fig. 2.-Method of recording movements of anterior leaf of mitral valve. Pulses of ultrasound are emitted from transducer on anterior chest wall and reflected back from the valve leaflet. Anterior movement of valve leaflet represents

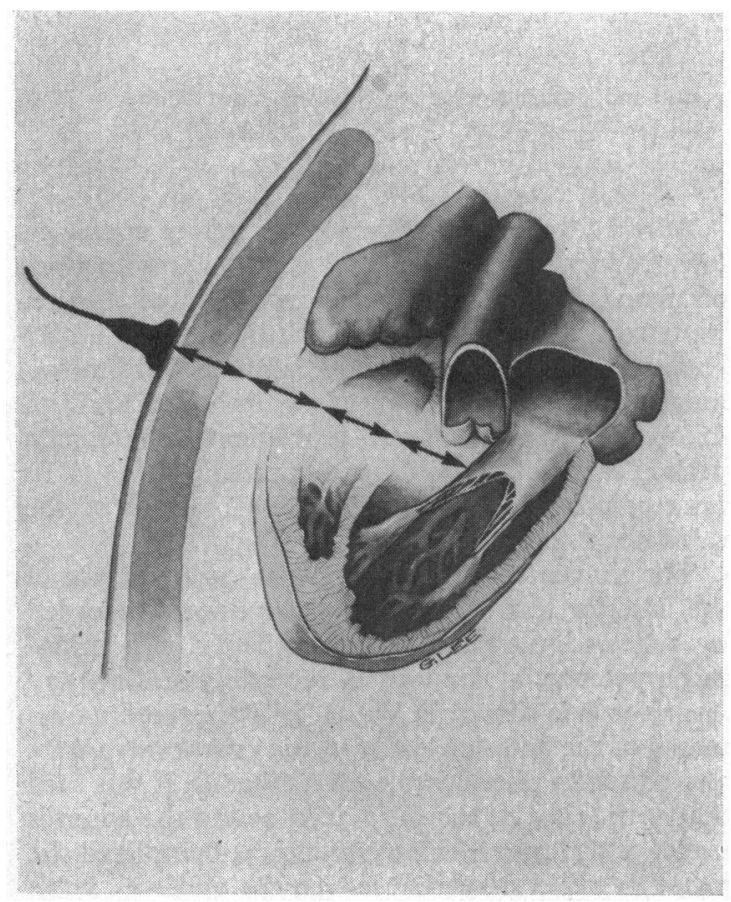
valve opening. sound were present in any of the 23 patients, but occasionally a high frequency low intensity click was recorded on the phonocardiogram at the time of the expected third heart sound. A third sound point was not seen in the apex cardiogram in any of the patients after mitral valve replacement; in the rapid ventricular filling phase of early diastole the apex moves rapidly outwards as before, but then the movement merges into the succeeding slow filling phase without the production of a diastolic peak (Fig. 5).

Aortic Valve Replacement (Table II). A peak in early diastole at $0 \cdot 12-0 \cdot 16$ sec. after aortic valve closure was present on the apex cardiogram in 6 of

TABLE II

APEX CARDIOGRAM AND PHONOCARDIOGRAM IN 8 PATIENTS AFTER AORTIC VALVE REPLACEMENT

\begin{tabular}{c|c|c}
\hline Patient & 3rd sound & $\begin{array}{c}\text { Height of 3rd sound point } \\
\text { Total ACG deflection }\end{array}$ \\
\hline V.B. & & \pm \\
G.B. & \pm & 9 \\
H.J. & - & 5 \\
D.o. & - & 14 \\
B.M. & - & 0 \\
T.M. & - & 1 \\
D.N. & - & 8 \\
M.T. & - & 0 \\
\hline
\end{tabular}




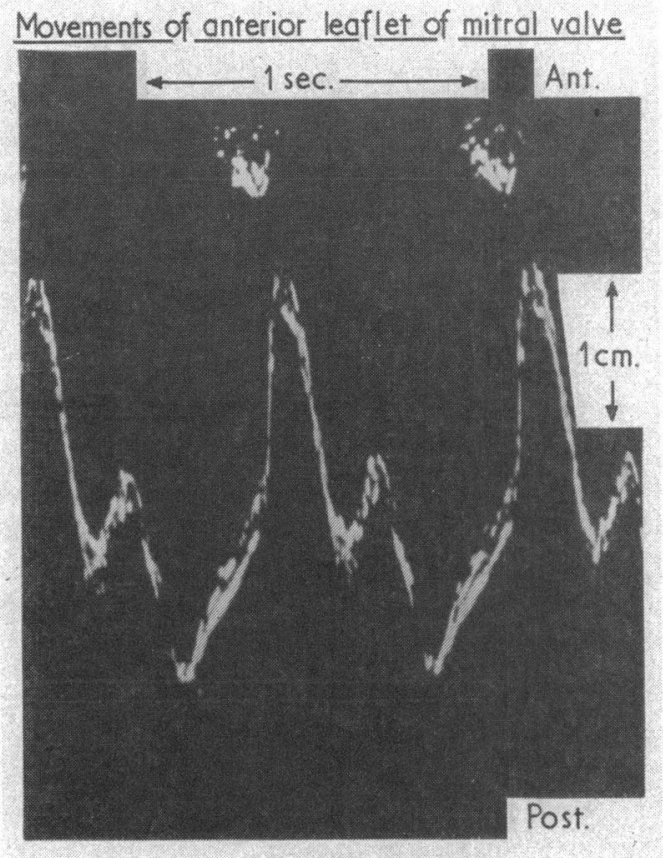

(A)

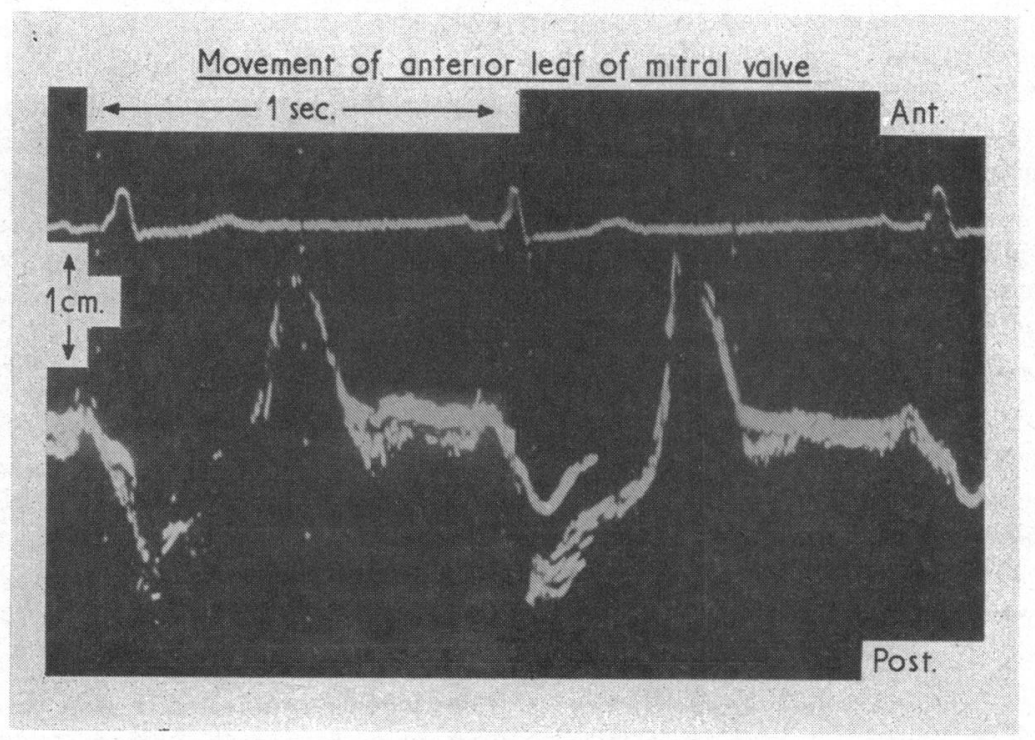

(B)

FIG. 3.-Ultrasound records of two complete cardiac cycles. (A) At slow recording speed. (B) At faster recording speed with simultaneous electrocardiogram. Anterior movement represents valve opening. 


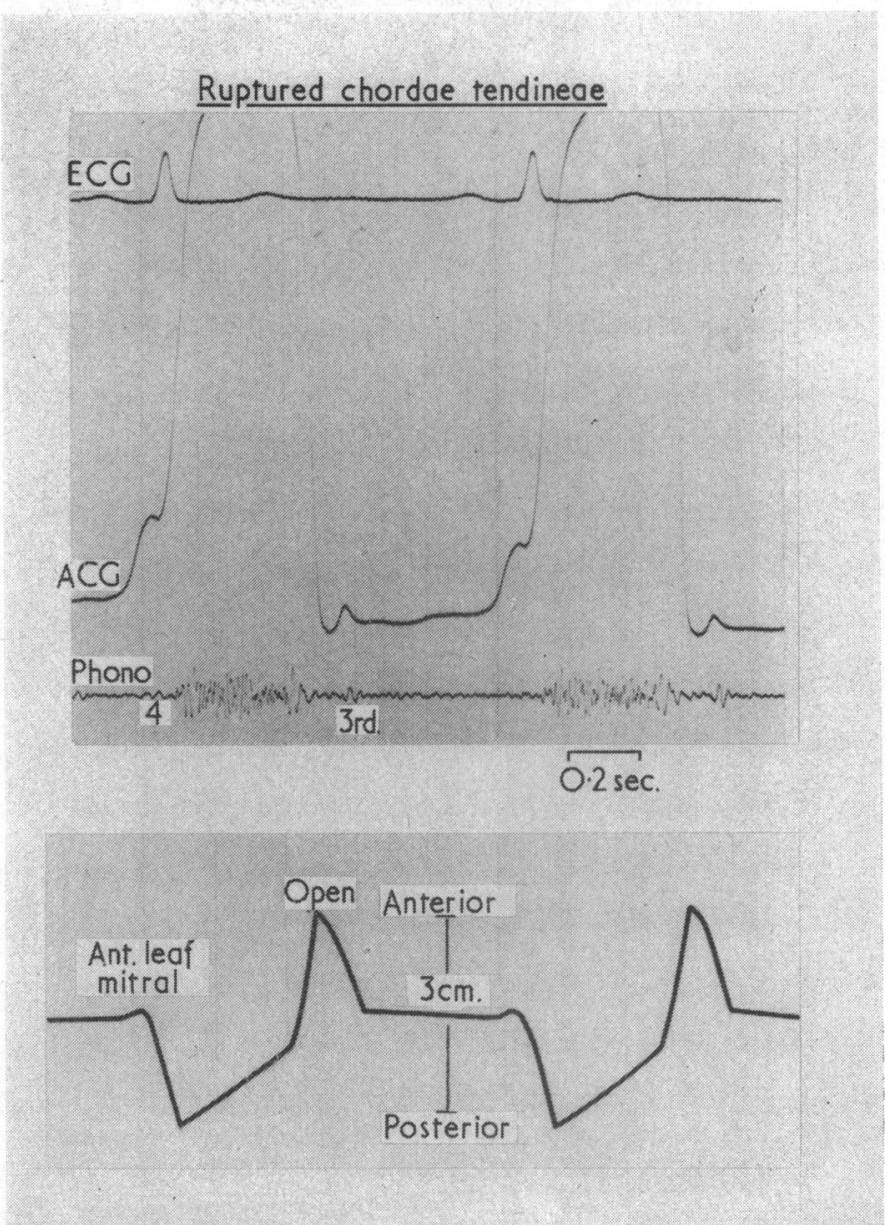

FIG. 4.-Movements of anterior leaf of mitral valve along with electrocardiogram (ECG), apex cardiogram (ACG), and phonocardiogram (Phono). Mitral valve in intermediate position at time of third sound.

the 8 patients studied after aortic valve replacement (Fig. 6). A typical third heart sound, consisting of low frequency vibrations at the time of this peak, was recorded in one.

\section{Discussion}

The third heart sound of severe mitral incompetence is loud, of low frequency, and is best heard at the cardiac apex. The sound occurs at, or very near to, the end of the early rapid inflow phase to the ventricles (Dock, Grandell, and Taubman, 1955). The mode of production of the third heart sound has been the subject of much debate, and considerable experimental work is available. The suggestion that the sound might arise from the impact of the ventricle on the thoracic cage can be dismissed, since the sound has been heard and recorded in intact and exposed hearts of dogs (Boyer, 1942). Potain (1900) suggested that the gallop sound was produced as the dilating ventricle quickly reached the point where the fibrous resistance of its walls limits its distension, and the sharp arrest of the ventricle caused a tension, a shock, and a gallop sound. Several authorities have since subscribed to this view (Kuo, Hildreth, and Kay, 1951; Crevasse et al., 1962), but the bulk of experimental work is against it. No evidence that any limit of distensibility of the left ventricle has been reached when the sound occurs is available. Furthermore, Dock (1959) was unable to produce audible vibrations when he subjected the left ventricular muscle in necropsy studies to changes in pressure of physiological magnitude.

Gibson (1907), from his studies of the jugular pulse wave, first suggested that the third heart sound 


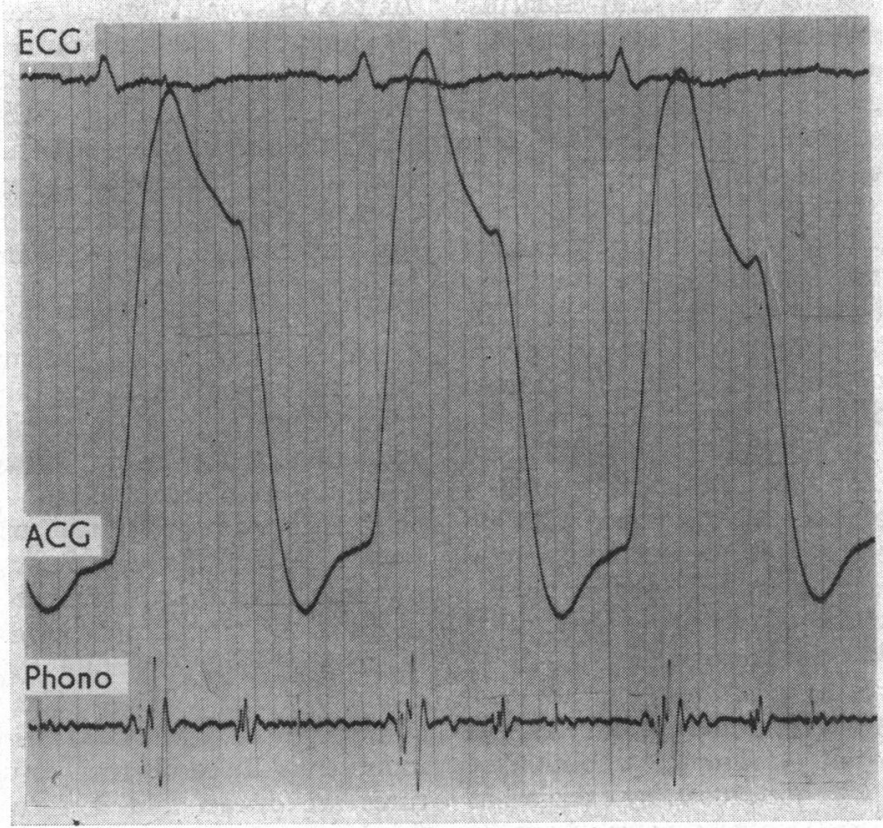

FIG. 5.-(Starr-Edwards mitral valve). No third sound and no diastolic peak on apex cardiogram after excision of mitral valve.

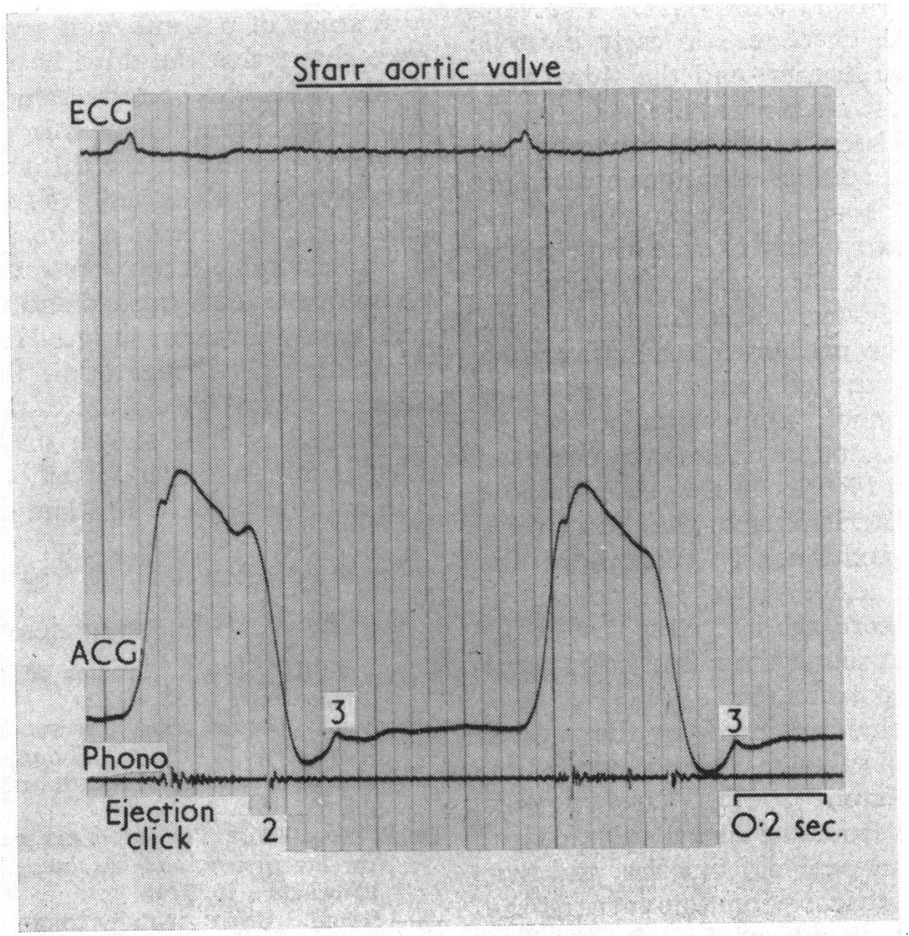

FIG. 6.-Diastolic peak on apex cardiogram recorded in patient with intact mitral valve. 
was due to sudden tensing of the atrioventricular valves, and most workers now agree that the tissues of the mitral valve can be set into vibration and that the audible physiological and pathological left ventricular third heart sounds in all probability arise from vibration of the mitral valve. Further support for this view is obtained in the present study. In all of the 23 patients examined before and after mitral valve replacement no third heart sound was heard after the mitral valve had been excised. The introduction of a Starr-Edwards mitral valve will produce a degree of obstruction to blood flow from the left atrium into the left ventricle (Morrow et al., 1964), but in many of our patients a rapid early diastolic filling wave is visible on the apex cardiogram after valve replacement, suggesting that no severe mitral valve stenosis is present. It is unlikely, then, that surgically induced obstruction to left ventricular filling accounts for the absence of the third heart sound in our patients.

Insertion of the prosthetic mitral valve has corrected the haemodynamic abnormality, and it might be postulated that in our patients the abolition of the third heart sound was not caused by excision of the mitral valve, but arose merely on the basis of relief of the regurgitation. To explore this possibility, patients with aortic valve disease were studied after the restoration of normal haemodynamics by the insertion of a prosthetic aortic valve. In several of these patients the characteristic early diastolic peak on the apex cardiogram and the third heart sound were still visible after operation.

Two ways have been suggested whereby the mitral valve may give audible vibrations at the time of the third heart sound. Gibson (1907) and Thayer (1909) postulated early closure of the mitral valve cusps. This view has received little support; most workers have shown that at the time of the third heart sound, the pressure in the left atrium is higher than that in the left ventricle (Crevasse et al., 1962). Furthermore, the coaptation of the pliable mitral valve cusps is unlikely to cause an audible sound (Dock, 1965). In the present study, the position of the anterior leaf of the mitral valve has been recorded continuously throughout the cardiac cycle by the technique of reflected ultrasound. From the recordings it is clear that at the time of the third heart sound the mitral valve cusps are not in the closed position (Fig. 4).

An alternative mechanism involving the sudden tautening of the mitral valve has been advocated by Dock (1959) and Nixon (1961). They suggest that the sound arises from the mitral valve cusps, chordae tendineae, and papillary muscles, and that these structures are set into vibration towards the end of the rapid filling phase of the left ventricle.
As the left ventricle fills, the apex of the ventricle descends and the atrioventricular ring moves upwards at considerable speed (Hultgren and Hubis, 1965). This elongation of the ventricle will cease when the mitral valve structures are placed under tension, and the abrupt retraction of the cardiac apex, seen on the apex cardiogram, may represent the limitation on downward movement imposed by the tautened mitral valve structures. The complete absence of apical retraction on the apex cardiogram after excision of the mitral valve would fit with this hypothesis.

In the present study it has been shown that abrupt retraction of the cardiac apex coincides in timing with the third heart sound. It is suggested that sudden tautening of the mitral valve, chordae tendineae, and papillary muscles induces vibrations in these structures, and that these vibrations are heard as the third heart sound. This suggestion is in keeping with currently accepted views on the origin of heart sounds. The concept of the first and second heart sounds arising from vibrations induced in the cardiac valves when the valve structures are drawn taut is extended to include the third heart sound.

\section{SUMMARY}

A study of patients with severe mitral incompetence shows that the third heart sound coincides in timing with abrupt retraction of the cardiac apex. After replacement of the mitral valve with a StarrEdwards prosthesis, the third sound and the apical retraction are abolished. The apical retraction is held to be the result of the sudden tautening of the mitral valve structures during the rapid filling phase of the left ventricle and the third sound may arise from vibrations induced in the mitral valve at this time. The suggestion that the third heart sound is caused by closure of the mitral valve cusps is rejected, as it is shown that at the time of the third sound the anterior leaflet of the mitral valve is in an intermediate position.

\section{REFERENCES}

Boyer, N. H. (1942). Studies on the third heart sound. Amer. Heart F., 23, 797.

Crevasse, L., Wheat, M. W., Wilson, J. R., Leeds, R. F., and Taylor, W. J. (1962). The mechanism of the generation of the third and fourth heart sounds. Circulation, 25, 635.

Dock, W. (1959). The forces needed to evoke sounds from cardiac tissues, and the attenuation of heart sounds. Circulation, 19, 376.

(1965). Heart sounds from Starr-Edwards valves. Circulation, 31, 801. 
-, Grandell, F., and Taubman, F. (1955). The physiologic third heart sound: its mechanism and relation to protodiastolic gallop. Amer. Heart f., 50, 449.

Fleming, J., and Hamer, J. (1967). Effect of propranolol on left atrial systole in ischaemic and hypertensive heart disease. Brit. Heart f., 29, 257.

Gibson, A. G. (1907). The significance of a hitherto undescribed wave in the jugular pulse. Lancet, 2, 1380.

Hultgren, H. N., and Hubis, H. (1965). A phonocardiographic study of patients with the Starr-Edwards mitral valve prosthesis. Amer. Heart f., 69, 306.

Kuo, P. T., Hildreth, E. A., and Kay, C. F. (1951). The mechanism of gallop sounds, studied with the aid of the electrokymogram. Ann. intern. Med., 35, 1306.
-, Schnabel, F. G., Blakemore, W. S., and Whereat, A. F. (1957). Diastolic gallop sounds; the mechanism of production. f. clin. Invest., 36, 1035.

Morrow, A. G., Clark, W. D., Harrison, D. C., and Braunwald, E. (1964). Prosthetic replacement of the mitral valve: operative methods and the results of preoperative and postoperative hemodynamic assessments. Circulation, 29, Suppl. 1, p. 2.

Nixon, P. G. F. (1961). The third heart sound in mitral regurgitation. Brit. Heart $\mathcal{F}$., 23, 677.

Potain, P. C. E. (1900). Les bruits de galop. Sem. méd., (Paris), 20, 175.

Thayer, W. S. (1909). Further observations on the third sound. Arch. intern. Med., 4, 297. 